\title{
Reflexiones sobre el motivo del viaje en el cine costarricense
}

\author{
Reflections About the Journey Motif in the \\ Costa Rican Cinema
}

\author{
Aarón Acuña Cordero
}

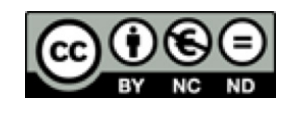

Esta obra está bajo una licencia Creative Commons Reconocimiento-No comercial-Sin Obra Derivada 


\title{
Reflexiones sobre el motivo del viaje en el cine costarricense
}

\author{
Reflections About the Journey Motif \\ in the Costa Rican Cinema
}

\author{
Aarón Acuña Cordero ${ }^{1}$ \\ Universidad de Costa Rica \\ Costa Rica
}

Recibido: 09 de marzo de 2019 Aprobado: 17 de julio de 2019

\begin{abstract}
Resumen
Este escrito corresponde a una serie de reflexiones sobre el motivo del viaje y las road movies en el cine costarricense, que nacieron de la investigación bibliográfica y fílmica previa a la realización de un mediometraje de ficción. Se caracterizan las road movies estadounidenses y latinoamericanas para, finalmente, esgrimir algunas razones que podrían explicar la continua utilización de este motivo en la cinematografía nacional.
\end{abstract}

Palabras clave: cine; costarricense; viaje; camino; ficción

\begin{abstract}
This paper includes a series of considerations about the journey as a motif and road movies in Costa Rican films, which came about from the previous bibliographical and filmic research necessary for the production of a mid-length film using this particular film sub-genre. It will characterize North and Latin American road movies, to finally propose some reasons that could explain this motif's recurrence in our national cinema.
\end{abstract}

keywords: film; costa-rican; journey; road; fiction

1 Director cinematográfico. Estudiante de la Maestría en Artes con énfasis en Cinematografía de la Universidad de Costa Rica. Licenciado en Cine y Televisión de la Universidad Véritas. Correo electrónico: 3audiovisual@gmail.com

ESCENA. Revista de las artes, 2020, Vol. 79, Núm. 2 (enero-junio), pp. 80-98 ISSN 2215-4906 


\section{Introducción}

En el año 2018, escribí y dirigí el mediometraje Hasta Llegar al Alba (Pérez y Acuña, 2018), el cual ha sido estrenado en Costa Rica, Cuba, Chile, Austria, Panamá, México, Bulgaria y Estados Unidos y recibió varios premios en festivales internacionales. La historia sigue a Carmen, la protagonista, durante una noche, mientras se traslada hacia la ciudad, con la ayuda de su hermana. Carmen busca una parte perdida de su pasado y esto desencadena un reencuentro entre ambas, que se desarrolla en ruta. Parecía obvio que me encontraba ante una historia de camino, de viaje y no pasó mucho tiempo para que me encontrara investigando las road movies, como subgénero cinematográfico capaz de guiar la narrativa y el acercamiento estético de la película.

La elección de un subgénero cinematográfico particular, probablemente, no debiera responder más que a una decisión personal, pero, en este caso particular, me llamó poderosamente la atención que, al comentar sobre mi intención de hacer de dicho audiovisual una road movie, se me respondiera con un tajante: "¿otra road movie costarricense?", acompañado con un talante medio entre la incredulidad y la decepción. Esta reacción sorprendería si pensamos que el motivo del viaje es tan antiguo como nuestra capacidad de contar historias. Pero, también es comprensible, al ver la forma cómo, en una cinematografía incipiente como la costarricense, existe una cantidad vasta de películas de ficción, cuyo motivo principal es, justamente, el viaje. Las razones por las cuales este tipo de historias y esta forma de hacer cine han permeado la imaginación de los realizadores y realizadoras costarricenses y en qué se diferencian de las creaciones del mismo subgénero en otras latitudes es la principal motivación del presente escrito.

Las reflexiones en este trabajo nacen como un sustento teórico y fundamentación al componente práctico de la realización del mediometraje y constituyó parte vital de mi tesis de Licenciatura en Cine y Televisión de la Escuela de Cine de la Universidad Véritas de Costa Rica (Acuña, 2018). Inicialmente, interesa realizar una conceptualización y caracterización de las road movies a nivel histórico al partir de las diferencias estilísticas que definen diversos periodos y lugares de producción. Esta es la base de la investigación teórica, la cual proviene, sobre todo, de una revisión bibliográfica y de visionados de largometrajes de ficción que van desde los trabajos seminales estadounidenses hasta su adaptación europea, latinoamericana y costarricense. Lo anterior, constituyó un insumo para plantear una propuesta visual y de arte en el mediometraje, que jugara con los elementos distintivos del género, pero, adecuados a nuestro país.

Posteriormente, interesa realizar un análisis de la relación del motivo del viaje con el cine costarricense, las razones de su recurrencia y la determinación de cuáles películas de ficción, dentro de nuestra cinematografía nacional, se catalogan como road movies y cuáles 
solo utilizan el motivo del viaje como un elemento más, sin ser el central. Se partió de la siguiente interrogante: ¿por qué viaja el cine nacional? La razón de tal argumentación proviene de la necesidad de conocer si hay algo dentro de nuestra idiosincrasia o, quizá, dentro de nuestro cine que haga de la película de viaje un género atractivo para los realizadores y guionistas nacionales. Esta sección se desarrolla mediante el análisis fílmico de cada una de las películas que serán citadas, especialmente, en las secuencias y narrativas dedicadas al viaje. Luego, son contrastadas con los elementos estilísticos y narrativos definitorios del subgénero, previamente fundamentados teóricamente. Dicha sección fue condicionante del approach a la dirección del mediometraje y su guion, puesto que un objetivo de la puesta en escena era que la necesidad del viaje no fuera azarosa, sino que existieran causas de peso, dentro de los personajes, que hicieran el viaje necesario y relevante.

\section{Las road movies}

Las road movies pueden ser definidas de muchas maneras y pueden comprender una enorme diversidad de películas. No basta tener un medio de transporte o un desplazamiento humano, para considerarse dentro de dicho subgénero. Para propósito de este ensayo usaremos la definición de Ron Eyerman y Orvar Löfgren (1995), según la cual una road movie es una película donde el camino y el viaje tienen una función central en la historia. Como subgénero, este se institucionalizó en las décadas de 1960 y 1970, en los Estados Unidos. Aunque, claramente, hubo antecedentes importantes durante toda la historia previa del cine (Berger, 2016a). La propia tradición cinematográfica americana cuenta con antecesores como It Happened One Night (1934) de Frank Capra, The Grapes of Wrath (1940) de John Ford o The Wild One (1954) de Lazlo Benedek.

No es de extrañar lo anterior, al asumir que el motivo del viaje ha sido, históricamente, uno de los más presentes en la creación narrativa de la humanidad. En mi época colegial, los dos relatos más importantes que los estudiantes de secundaria de mi generación debíamos leer eran La Odisea de Homero y El Quijote de Cervantes; obras literarias en las cuales el viaje constituye un tema central que impulsa el relato. Mi visionado de los filmes predecesores de las road movies me aclara que, si bien estas eran narrativas basadas en un viaje, la iconografía, los personajes y las características definitorias del género no habían aparecido aún. Si bien el motivo del viaje y el cambio interno en los personajes al llegar de un punto al otro -la acción transformadora del camino- estaba presente, este se enmarcaba en otros géneros, como el western o el melodrama.

Pero, ¿cuáles son esas imágenes que asociamos a las road movies? Según el artículo Romancing the road (Eyerman \& Löfgren, 1995), las "historias de camino" (road stories) han sido hechas y reinterpretadas una y otra vez. De forma que, casi cualquier persona puede 
cerrar sus ojos y contemplar las imágenes de automóviles con asientos de cuero dañados por el sol, cruzando carreteras con música a todo volumen. Puede imaginar los sórdidos hoteles de paso, los sonidos de los televisores al fondo, los sucios bares, la gasolinera en el medio de la nada, los cafés en esquinas y las maternales meseras de una América (en referencia a los Estados Unidos), que Edward Hopper imaginó tiempo atrás. Estas imágenes tan presentes en la mente de los cineastas y cinéfilos de todas partes del mundo tienen un génesis histórico claro. Tras el crecimiento económico de la posguerra en Estados Unidos, la creación de autopistas proliferó. Se creó la famosísima Ruta 66, homenajeada en la seminal novela On the Road (1957), de Jack Kerouac que mostraría "el camino" para afianzar el futuro género cinematográfico (Berger, 2016a). Tal camino, parecía ofrecer aventura y emociones. Esto motivó a los jóvenes estadounidenses, en las décadas de los cincuenta y sesenta, a conocer partes de su país que podrían desaparecer ante la creciente industrialización y urbanización. Estos eran los Estados Unidos que tomaron cineastas como Jim Jarmusch, Aki Kaurismakki y Wim Wenders con el fin de mostrar personajes que dejaban atrás lo mundano y burgués, para perseguir algo que percibían como más significativo. La road movie, por lo tanto:

se inscribe en el proceso de la mecanización del desplazamiento humano, confluyendo su auge en los años 60 y 70 con la crisis de identidad desencadenada a partir de la debacle de la Guerra de Vietnam y con el surgimiento de una contracultura que critica el sistema establecido y sus valores (Berger, 2016b, p. 163)

En la teoría de la historia del cine, el reconocimiento de la road movies culmina con Easy Rider (1969) de Dennis Hopper, la cual, gracias a la crítica fílmica, se convierte en la película referencial del género (Berger, 2016b). Basta ver a Peter Fonda y Dennis Hopper, con su look de hippies delincuentes, en sus choppers con motivos estadounidenses y el potente rock de Steppenwolf tocando Born to be Wild para darnos cuenta de que estamos frente a un estilo de cine con reglas propias. La misma letra de la canción parece una declaración de principios y fundamentos de la road movie.

Get your motor runnin', head out on the highway, lookin' for adventure and whatever comes our way. Yeah Darlin' go make it happen! Take the world in a love embrace fire all of your guns at once and explode into space [Prende tus motores, sal a la carretera buscando aventuras y lo que se aparezca en tu camino. ¡Sí nena!, ve y haz que pase, toma el mundo en un abrazo de amor, dispara todas tus pistolas al mismo tiempo y explota en el espacio] (Bonfire, 1968).

Para Berger (2016a), este género es conocido como un pilar de la cinematografía estadounidense, donde el viaje, la movilidad, el tiempo y el espacio, así como la experiencia de estar "en ruta" son preocupaciones centrales de sus protagonistas. Asimismo, ha sido 
adaptado por cineastas de casi cualquier país, como una versión audiovisual de la tradición literaria de la Bildungsroman (conocida en inglés como "coming of age story"). Especialmente, con la intención de usar la metáfora del viaje para tratar cuestiones de búsqueda de identidad individual, comunal y nacional.

Para abordar este tipo particular de películas y aterrizarlo en nuestros horizontes mesoamericanos -y en mi particular experiencia como director de Hasta Llegar al Alba (2018) - hay que remitirnos a sus características fundamentales. Para esto, tuve la placentera obligación de observar un gran número de filmes de camino, para contrastarlos con las opiniones de autores especializados y así distinguir los rasgos definitorios de toda road movie. Así, para esbozar a posteriori las particularidades del género en Estados Unidos, Latinoamérica y Costa Rica.

Algo claro, en prácticamente toda representante del género, es que el camino y el medio de transporte se transforman en una metáfora de la vida misma (Eyerman \& Löfgren, 1995). Ejemplos hay tantos como películas. Pero, una que me ha impactado particularmente es la genial Paris-Texas (1984) de Wim Wenders. Nuestro ¿héroe?, Travis Henderson, está perdido en la vida, por ende, vaga por un desierto a pie, buscando un lugar casi mítico, conocido como París, Texas, para después, reencontrarse con algo que cree le dará alguna sensación de pertenencia. Luego de una gran travesía, tanto personal como espacial, logra localizar a su familia y muy especialmente a su exesposa Jane, a quien logra reunir con el hijo de ambos. A pesar de esto, él se queda con su culpa y su pasado, en la soledad. Travis, interpretado por el gran actor H. D. Stanton, se manifiesta en su totalidad en ese camino infinito que parece recorrer. Travis huye de todo, por miedo a reencontrarse con su pasado, cuando lo encara frente a frente, hay un espacio para la redención, aunque es imposible borrar lo hecho. Por su parte, Hasta Llegar al Alba (2018) buscaba esta metáfora conscientemente. Si bien la búsqueda de mi protagonista reside en cerrar un capítulo específico de su vida, proveniente de una relación amorosa pasada y su fracaso. La idea era que el viaje fuera narrando con imágenes partes relevantes de la vida de ella y que el espectador llegue a conocerla a través del camino y sus interacciones con los demás personajes que encuentra en ruta.

Aunado a las carreteras aparentemente interminables y a los espacios abiertos, los medios de transporte son, sobre todo, los que desempeñan un papel primordial en la iconografía de estas películas. Los hay a pie, en tren, motocicleta, en bicicleta y, hasta, en burro. Pero, el medio favorecido es el automóvil, con lo cual se rinde homenaje a la velocidad y se convierte en símbolo de libertad, de poder, de estatus y del individualismo. Se afirma que el espacio del medio de transporte "como extensión protética del cuerpo humano, engendra el híbrido conductor-máquina" (Berger, 2016b, p. 164). Esto nos da un mundo con un afuera, 
que es el camino, y un adentro, representado por la dualidad del chofer y el carro. En definitiva, "la road movie siempre funciona entre estas dos polaridades: el mundo interno y el mundo exterior" (Chanan, 2016, p. 181). El medio de transporte y el camino se convierten en personajes, de los que se habla cual si fueran seres humanos. Esta caracterización de ambos elementos es clara en la más famosa novela de camino, On the Road (1957) de Jack Kerouac, la cual ayudó a romantizar la Ruta 66 y, en general, brindó un imaginario a las subsecuentes road movies. Esta ruta, su transformación e imágenes siguen siendo, actualmente, gran parte de la ambientación de las road movies dentro y fuera de los Estados Unidos (Eyerman \& Löfgren, 1995).

En la narrativa de cualquier viaje, el vehículo constituye, efectivamente, un personaje en sí, que conlleva de forma implícita la identidad de los protagonistas. La motocicleta en Easy Rider es icónica de la contracultura individualista occidental de la década de 1970 en Estados Unidos. En los ejemplos latinoamericanos, el vehículo simboliza más concretamente el subdesarrollo. Todos estos modos de transporte se vinculan con ciertas perspectivas hacia el mundo que los protagonistas están ejemplificando. También, determinan el movimiento de la narrativa misma (Chanan, 2016). Los automóviles en las películas estadounidenses se encuentran desde deportivos y clásicos hasta modernas camionetas. Mientras que, en Latinoamérica se favorece la movilidad a pie o los autos más humildes. El cineasta nacional Hernán Jiménez lleva tres películas donde utiliza un carrito destartalado de más de 20 años de antigüedad, para representar el subdesarrollo costarricense como lo expone en sus historias de camino.

El éxito de la road movies transcurre como consecuencia del establecimiento del automóvil como medio de transporte de masas al alcance de cualquier ciudadano. El hecho de poseer un vehículo propio empezaba a garantizar una libertad de movimiento individual hasta entonces desconocida (Berger, 2016b). Es innegable que muchas películas del género son de bajo presupuesto, de acuerdo con sus mercados cinematográficos específicos. La fotografía dentro del automóvil y la baja cantidad de personajes que caben en un medio de transporte como este han brindado a los cineastas la posibilidad de contar con diversas locaciones y con una narrativa completa, sin necesitar derrochar mucho dinero.

Para Eyerman y Löfgren (1995), al bajo presupuesto y la resonancia cultural del género, debe agregarse el mercado relativamente seguro que hace de la road movie un género "seguro", en el cual la pregunta de los realizadores se distancia de las ventas y el "éxito". Más bien, se acerca a la preocupación sobre si la película será muy predecible. De hecho, en la road movie, si el tema no se tiene claro y la historia no está bien definida, se puede caer en clichés con enorme facilidad, o los eventos pueden estar solamente puestos en escena por decisión del director, sin que el camino represente un elemento que haga avanzar la historia o que los protagonistas se transformen. 
Ahora bien, no hay que confundir lo antojadizo y gratuito de algunos argumentos con lo azaroso. Mientras que, lo primero va en detrimento de la exploración del personaje en ruta, lo segundo es una característica del género, asociado con el encuentro. Esto convierte al camino en un buen lugar para acontecimientos fortuitos. En el camino, se cruzan las trayectorias de personas muy variadas, de diferentes clases sociales, niveles, religiones, naciones, edades, que coinciden en un punto único en el tiempo y el espacio. Gente que, normalmente, se mantiene separada por distancias sociales y espaciales se encuentra por casualidad. Puede ocurrir cualquier contraste, pueden confluir y cruzar los destinos más variados (Berger, 2016a).

Así, la narrativa consiste en la acumulación de incidentes de carácter accidental, sin ningún orden necesario, porque aquí no hay causa y efecto impulsando un argumento. Se trata de una forma narrativa dispersa con antecedentes en géneros literarios como la novela picaresca... En definitiva, el mundo -el espacio representacional- de la road movie es abierto, extendido, habitado por otros, sorprendente, arbitrario, muchas veces chocante y violento (Chanan, 2016, p. 182).

Una característica importante de las historias de camino es su ambigüedad. El camino, sea cual sea su ruta, siempre está lleno de riesgos, pero, igualmente, rebosante de esperanza por el futuro (Eyerman \& Löfgren. 1995). Basta visionar la ya mencionada Easy Rider o la ópera prima de Terrence Malick, Badlands (1973) para saber que el pesimismo o la incertidumbre juegan un papel tan importante como la esperanza, al conceptualizar el futuro. La investigadora Verena Berger (2016a, 2016b), quién ha seguido y estudiado profundamente este género, desde una perspectiva teórica, histórica y comunicacional, también define como característica la siempre presente crítica cultural, individual y social que proviene de la exploración de las regiones por donde se mueve el protagonista de las historias de camino. Esto hace, según sus investigaciones, que el formato sea ideal para lidiar con el retrato cinemático del arraigo y desarraigo, así como del sentido de pertenencia a un tiempo y espacio. Desde sus inicios, las road movies se han constituido alrededor de la nostalgia, ya sea de la libertad perdida o de la oportunidad pasada; lo que pudo ser y no fue. Esto se manifiesta en el género de las road movies actuales o de los últimos años, alrededor del mundo. Siempre hacen referencia directa a sus antecesoras (Eyerman \& Löfgren, 1995).

Un rasgo distintivo que explica, en parte, la popularidad de la road movie y su implementación en cinematografías diferentes al estilo estadounidense es la paradoja de que el género puede lograr ser familiar y/o exótico. Por otro lado, la popularidad del formato radica en su capacidad de retratar sociedades en estado de tránsito, entre la tradición y la modernidad. Una disyuntiva que, desde la caída del Muro de Berlín y la disolución del modelo socialista de la Unión Soviética se ha intensificado, a partir de la implícita expansión de la globalización neoliberal (Berger, 2016b).

ESCENA. Revista de las artes, 2020, Vol. 79, Núm. 2 (enero-junio), pp. 80-98 
A manera de resumen, podemos definir como características de este subgénero que el viaje es central al relato y existe una serie de códigos estéticos particulares del subgénero. El camino representa una metáfora de la vida misma, el medio de transporte se convierte en un personaje. Es un subgénero seguro y de bajo presupuesto, tiene una narrativa llena de incidentes y eventos azarosos, contiene la ambigüedad del camino, la crítica social y cultural, la nostalgia y una mezcla entre exotismo y familiaridad.

\section{La road movie estadounidense}

Estados Unidos es el lugar donde este género se consolida y prospera, mientras el western entra en decadencia. Sam Peckinpah crea The Wild Bunch, considerado por muchos el último auténtico western, en 1969, un año después de lo que se considera la road movie paradigmática: Easy Rider (Chanan, 2016).

Common to most of these films is that they are about escape from the claustrophobia of petit-bourgeois life, from corruption and injustice and from an intolerant normality ... The basic tone of these films is pessimistic [Lo más común de estos filmes es que tratan sobre el escape de la claustrofobia ocasionada por la vida pequeño-burguesa, de la corrupción y la injusticia de la intolerable normalidad ... El tono básico de estos filmes es el pesimismo] (Eyerman \& Löfgren, 1995, p. 62).

La pareja de Badlands, los hippies de Easy Rider, el chofer y el mecánico de Two-Lane Blacktop (Laughlin \& Hellman, 1971) y hasta las amigas en Thelma and Louise (Scott, 1991) son individualistas, rebeldes, inadaptados o, incluso, criminales. Buscan una ansiada libertad, muchas veces de la peor forma posible. Para el cine estadounidense, el concepto de libertad y huida es muy importante. A diferencia, por ejemplo, de la tendencia europea de enfocarse en el movimiento de un lugar a otro. Esto por razones prácticas y donde, usualmente, sus protagonistas son ciudadanos ordinarios. Muchas road movies discuten y deconstruyen el concepto de hogar, sea para escapar de él, buscar uno nuevo o para matizar la tensión entre lo cercano y lo lejano. El automóvil o medio de transporte se convierte en un mini-hogar temporal. Mientras que, en las películas estadounidenses se busca la desintegración del concepto de hogar, las europeas se enfocan en la búsqueda de un hogar nuevo, ya sea por migración o por regreso tras un proceso de sanación (Berger, 2016a).

\section{La road movie latinoamericana}

La siguiente caracterización sobre la adaptación latinoamericana de las road movies proviene de la investigación de Verena Berger: La road movie latinoamericana en el contexto global, publicada en la revista Travelling Cinema (2016b). Dado que la road movie se caracteriza por la representación del movimiento en el espacio y en el tiempo, 
necesariamente, tiene que encontrar formas particulares para retratar la velocidad. En contraste con la presencia primordial del automóvil o de la motocicleta, como reflejo tecnológico de la road movie en Estados Unidos, el cine latinoamericano destaca por retratar una movilidad fragmentada o ralentizada.

¿Qué significa esto? Berger (2016b) divide las road movies en tres categorías, a saber: movilidad rápida, fragmentada y ralentizada. La categoría rápida hace alusión a la forma estadounidense de filmar los caminos y películas, como Cleopatra de Eduardo Mignona (2003), que se caracterizan por la imitación del modelo estadounidense. A nivel iconográfico, otro ejemplo es Y tú mamá también (Vergara \& Cuarón, 2001) donde Alfonso Cuarón consigue crear una imitación del prototipo americano. A partir del automóvil, la carretera y la movilidad acelerada, la cámara privilegia la visualización de los personajes en el espacio cerrado del automóvil, junto con la integración de la toma del espejo retrovisor y de la carretera vista desde el volante. Integra travelling shots y panoramas de paisajes característicos para el género fílmico. Incluso, el automóvil utilizado por los personajes de dicho filme, aunque viejo y prestado es un clásico Cadillac estadounidense.

Aparte de la imitación, en Latinoamérica se destacan los viajes en medios de transportes públicos, como el autobús o el tren. La fragmentación y diversificación de los modos y medios de movilidad dinamizan la trama, a través de montajes episódicos y actúan como eslabones entre los espacios atravesados y el estado interior de los protagonistas. Dentro de la cinematografía de América Latina, abundan las road movies que destacan por su alternancia de modos y medios de transportes y fragmentación de la movilidad. El ejemplo más conocido es la película El viaje de Fernando Solanas (1992) y Diarios de motocicleta de Walter Salles (2004), donde la movilidad precaria -a veces incluso accidentada- se da a través de la diversidad de los medios de transporte.

Como tercera categoría, se encuentran películas donde los medios de transporte quedan reducidos al valor de mera utilidad para superar las distancias. La movilidad se restringe a lo físico, mientras las carreteras, en el supuesto de que existan, se convierten en caminos no asfaltados o en espacios abiertos. En América Latina, se rompe, mayormente, la idea etnocéntrica de la linealidad de espacio y tiempo. En O caminho das nuvens (Barreto, Gastal \& Amorim, 2003), una familia con cinco niños recorre un trayecto de 3000 kilómetros en bicicleta para encontrar mejores condiciones de vida en la metrópolis. A la inversa, en Central do Brasil (Salles, 1998) una señora acomodada, de ciudad, camina y recorre poblados para devolver un niño al pueblo donde habita su padre. Así, se encuentra a ella misma, al comprender su soledad en el trayecto. Otro ejemplo interesante es el de Los viajes del viento (Bustamante, Galleto \& Guerra, 2009), la cual es catalogada por la mayoría de los críticos como road movie. Lo que diferencia esta película de la iconografía tradicional es la 
forma de desplazamiento: el protagonista, Ignacio, va en burro y Fermín, su joven acompañante le sigue caminando. En este contexto, la road movie latinoamericana tiene especial interés por el proceso de adaptación de aquel género típicamente norteño a la realidad y al imaginario latinoamericano.

\section{El viaje en el cine costarricense}

Vuelvo a la respuesta de mis interlocutores al saber que haría este mediometraje: ¿otra road movie? Primero, es necesario aclarar que, si bien el motivo del viaje es una tendencia constante en la creación cinematográfica costarricense -al punto de ser la más evidente y repetitiva- no considero, necesariamente, que la mayoría de películas viajeras nacionales sean road movies. Esto porque el viaje no transforma, precisamente, a sus personajes, el medio de transporte y el camino no se vuelven personajes en sí mismos, ni se hace del camino una metáfora de la vida. Además, carecen de la iconografía característica y no se apegan a las particularidades del subgénero, expuestas en secciones anteriores. Sin embargo, casos abundan y lo que más interesa es dilucidar las razones por las cuales, evidentemente, el motivo del viaje es vital para entender la cinematografía costarricense. Para recolectar información y generar una discusión con respecto al motivo del viaje en el cine nacional, me remito muy especialmente al libro Fabulaciones del nuevo cine costarricense (2016), de la historiadora e investigadora María Lourdes Cortés, específicamente, al capítulo titulado: "El viaje en un país inmóvil", unido al visionado de los respectivos filmes.

El filme que inaugura el cine costarricense vaticina lo que está por venir, ya que el viaje es, justamente, el desencadenante de la trama principal. El Retorno de A. F. Bertoni (1930) cuenta la historia de Rodrigo, quien, sobre el tren, como emblemático símbolo del progreso que es, se dirige del campo idílico de su infancia, hasta la problemática ciudad. Ahí, tras una serie de dificultades se da cuenta de que "no hay lugar como el hogar"; nueve años antes de que Dorothy en el Mago de Oz inmortalizara tal idea en el cine. Con un argumento casi idéntico, tan solo separado por 87 años y un viaje transcontinental, Miguel Gómez nos presenta el éxito taquillero que fue Maykol Yordan, de Viaje Perdido (2014). El personaje titular sale del campo por la fortuna de ganarse un sorteo y de paso encuentra, por suerte y casualidad, la forma de ganar mucho dinero y salvar la finca de su familia.

Al contrario de El Retorno, a Maykol Yordan sí la podríamos catalogar como una road movie, en tanto el viaje es una parte central de la trama. Aunque este no tiene efecto alguno sobre el personaje, que vuelve siendo el mismo campesino tonto que era al inicio. La película cierra con una paráfrasis de "no hay lugar como el hogar", con el agravante de que, durante todo el metraje, Europa pareciera ser el lugar más próspero, hermoso y lleno de gente amable que hay en el mundo. Mientras que Costa Rica es un lugar sin oportunidades, 
lleno de gente aprovechada y donde surgir es casi imposible. Realmente el gran logro de salvar su finca, se da solamente por las raíces familiares europeas, que eran desconocidas para el campesino.

Esa imagen de la Costa Rica pobre, sucia y sin oportunidades, se ve en otra película exitosa, que, si bien no es road movie, tiene el viaje como un tema central y es El regreso (2011) de Hernán Jiménez. En esta, Antonio, interpretado por el mismo director, vuelve de la glamorosa Nueva York, donde se gana la vida como escritor, a un barrio josefino, donde casi nadie podría ganarse la vida como escritor. Se da cuenta de que el país es pobre, peligroso y con una mala planificación urbana, lo cual nos hace preguntarnos ¿hace cuánto se fue este muchacho para no saber cómo es Costa Rica? Además, Jiménez se ha decantado por el cine de viajes, ya que su primera película, así como la más reciente, si podrían caber en el amplio cajón de las road movies.

Su ópera prima A ojos cerrados (Rivera, García \& Jiménez, 2010) le propone a Gabo y Delia la tarea de esparcir las cenizas de la esposa de él y abuela de ella en el mar Caribe. Por ende, ambos enfrentan dificultades y parten hacia Puerto Viejo de Limón, para cumplir ese último deseo. Los personajes no se transforman, permanecen iguales durante la película, al punto que Gabo ni siquiera logra desapegarse de las cenizas. Pero, el camino y el estar en ruta, en un lugar diferente al común, resulta primordial para contar este episodio de la vida de los protagonistas. En su más reciente Entonces nosotros (Cole, Ávila-Tacsan \& Jiménez, 2016), el viaje es visto como una forma de solucionar los problemas de una pareja atribulada, al final de su relación. Es fácil identificar que viajar se ve como una forma de llegar más "alto", a ese algo mejor que no se sabe explicar bien, como lo menciona el personaje de Teresa en La Insoportable Levedad de/ Ser de Milan Kundera. A pesar de emprender el viaje, la pareja solo empeora las cosas y terminan de forma inevitable.

Por su parte, la película Amor viajero de Miguel Gómez (2017) nos presenta un argumento similar a Entonces nosotros (2016), pero con final feliz. Una pareja viaja a Europa para salvar su relación. Ven lugares, turistean, pero la resolución no se da por el viaje, sino por un acto prácticamente criminal, cuando el protagonista masculino rapta la tarjeta de crédito de su exnovia y la fuerza a compartir con él. Para Cortés (2016), tanto en El Cielo Rojo (2009) como en El Fin (2012), ambas de Miguel Gómez, los viajes tienen una importancia como medio de catarsis, como una forma de los personajes de liberarse de sí mismos y volver renacidos. Los viajes son muy breves para considerarles road movies, pero, estas películas -junto con la ya mencionada Amor viajero (2017)- muestran una predilección de Gómez por el cine de viajes. Aunque las vagas justificaciones de estos viajes parecieran decir que más que viajar para hacer cine, a Gómez le gusta hacer cine para viajar y que una película, incidentalmente, suceda mientras se pasea.

ESCENA. Revista de las artes, 2020, Vol. 79, Núm. 2 (enero-junio), pp. 80-98 
El viaje es también central en El lugar más feliz del mundo (2015) de Soley Bernal, donde un grupo de comediantes "buenos" son amenazados de muerte. Además, un grupo de "gente mala" cierra su canal de televisión. La crítica la catalogó como una película maniquea, donde el guion no logra justificar un viaje, el cual se emprendió para buscar el lugar más feliz del mundo. Los personajes no cambian y el giro del final se da por suerte, sin que el viaje influya en el desenlace. En este caso, es difícil saber si nos encontramos frente a una road movie o no. Aunque el viaje es, definitivamente, central en el relato, este podría resolverse de otra manera, de forma que, se restaría importancia al motivo. Para la consideración de este trabajo, no es necesariamente una película de camino, aunque el viaje es muy importante para su desarrollo.

Los cuatro ejemplos más representativos de la road movie en Costa Rica los encuentro en La Apuesta (1968) de Miguel Salguero, El camino (2009) de Ishtar Yasin, Tercer mundo (2009) de César Caro y Viaje (2015) de Paz Fábrega. En La Pantalla Rota (2005) de María Lourdes Cortés, se define a La Apuesta (1968) como el primer road movie tico. Efectivamente, este largometraje silente en $16 \mathrm{~mm}$ cuenta la historia de dos amigos que apuestan por quién será el primero en llegar, a bordo de sus Jeeps, hasta Limón, desde San José. Aunque existe una historia de amor y celos subyacentes, el camino es el motor fundamental de la historia, así como de las peripecias que sufren los viajantes. Al final, de forma casi mágica, los problemas de las parejas y sus familias se resuelven solos, sin mediar de forma relevante el camino, que ocupó la mayoría del tiempo de pantalla. Podríamos decir que muchos elementos como el camino azaroso y ambiguo, así como el protagonismo de los medios de transporte, le definen dentro del subgénero.

Tercer mundo (2009) consta de tres historias diferentes, relacionadas al motivo del viaje de una u otra forma. Cada historia muestra jóvenes que desean emigrar hacia otro país y que ven este movimiento como la respuesta a sus problemas. El chileno, Juan, cree que un meteorito impactará su país, por lo cual se impone la tarea de viajar. Amaya, en Bolivia, quiere encontrar a su padre, para lo cual necesita emigrar a Costa Rica. El tico, Richi, tras una decepción amorosa, busca emigrar hacia donde ningún hombre lo ha hecho nunca: otro planeta. Al igual que en El camino (2009), acá los motivos son fuertes y definidos, al menos para los personajes, que sienten que algo mejor habita allá afuera. Aunque la respuesta al final no se da en el escape, sino, más bien, en enfrentar los problemas en casa.

En El camino (2009) encontramos una película de movilidad ralentizada, según la clasificación de Berger, donde los personajes viajan en dos maneras. Por un lado, los hermanos Saslaya y Darío van en búsqueda de su madre y de una vida lejos del abuso y la carencia que hay en su hogar. Pero, en el proceso se trasladan de Nicaragua hacia Costa Rica, llevando consigo muchos acompañantes en la tarea impuesta de emigrar y encontrar 
mejores oportunidades. Al contrario de la mayoría de películas que se han mencionado, en El camino sí encontramos una razón clara y un viaje transformador. La historia es lenta, característica de las películas latinoamericanas sobre migraciones, se encuentra llena de simbolismos y poesía. Al tomar elementos del documental, Yasin presenta a muchos viajeros en su paso por las fronteras y sus encuentros con dos países íntimamente relacionados. La cámara y la forma de mirar cada país nos muestran que, en esta película, se encuentra, igualmente, el elemento de crítica social y cultural, acompañado de la metáfora de la vida del migrante, personificada en los hermanos viajeros. Los riesgos y las ambigüedades del camino son muchas.

Viaje (2015) nos presenta a Luciana y Pedro, dos jóvenes que, tras conocerse en una fiesta se van conociendo cada vez más íntimamente y se van enamorando. Se presentan dos viajes importantes y ambos son impuestos por las circunstancias. Pedro debe ir al Rincón de la Vieja a trabajar en su tesis y Luciana debe irse a vivir con su novio a Londres. Pero, ella decide acompañar a Pedro en el primer viaje a la zona para vivir una última aventura, antes de que su mundo cambie. Durante el viaje, los personajes se transforman y aunque solo cuentan una pequeña parte de sus vidas, los momentos azarosos y el estar lejos del hogar van conformando una relación. Es interesante notar que Fábrega cambió el final para el público costarricense, ya que, en el estreno nacional, Luciana decide irse, pero regresa en búsqueda de Pedro. Con ello, se modifica el final triste por uno "feliz", para el público tico. En su estreno en el Tribeca Film Festival, Luciana se va y ahí termina la película.

El hecho de hacer un cambio para el público nacional resulta muy revelador, debido a que en los cuatro casos de road movies, previamente mencionados, los personajes se percatan de que, en el viaje, en el camino, la huida o la emigración no está la respuesta. A pesar de la apuesta por el viaje, los problemas familiares se resuelven sin necesidad de mediación del camino: Saslaya termina capturada por una red de prostitución y nunca encuentra a su madre; los jóvenes de Tercer mundo no logran emigrar y buscan las respuestas en sí mismos, y Luciana vuelve al amor de Pedro y a su país. Algo queda del "no hay lugar como el hogar" que mencionamos en El retorno (1930) y Maykol Yordan (2014), en estas películas.

En resumen, podríamos catalogar, según los criterios previamente expuestos y al tomar en cuenta hasta el año 2018, como road movies a La apuesta (1968), El camino (2009), Tercer mundo (2009), A ojos cerrados (2010), Maykol Yordan (2014), Viaje (2015), Entonces nosotros (2016) y Amor viajero (2017). Por otra parte, como películas donde el viaje tiene una importancia grande, pero que no son road movies, se pueden mencionar El Retorno (1930), Puerto Padre (2013), El cielo rojo 1 (2008), El cielo rojo 2 (2015), Agua fría de mar (2010), El último comandante (2010), El regreso (2011), El fin (2012), Italia 90 (2014), Nina y Laura (2015) y El lugar más feliz del mundo (2015). 


\section{Conclusiones, ¿por qué viaja el cine nacional?}

Los siguientes apartados resumen la visión como autor y consumidor de cine nacional, sobre las principales razones deducidas. Esto, tras visionar las historias de camino costarricenses y leer sobre sus producciones y características.

\section{La realización de que no hay lugar como el hogar}

Muchos de los filmes mencionados viajan por diferentes razones, pero, terminan volviendo al punto inicial o en la realización de que los problemas deben resolverse en casa. Apreciar lo que tenemos como país, contrastándolo con la situación de otros es algo recurrente en nuestro acervo cinematográfico. El paralelismo anterior entre El Retorno (1930) y Maykol Yordan (2014) muestra cómo, a lo largo de los años, la vuelta al hogar constituye una parte importante de la identidad de nuestros personajes. Más allá de un regreso a casa, esto resulta una vuelta a al pasado de una Costa Rica idealizada, alejada de la naturaleza tensa y violenta de la actualidad. El campo costarricense es visto como una imagen de perfección, con unos valores y un estilo de vida al cual hay que volver. El campo costarricense para los personajes viajantes ticos es el Kansas de Dorothy.

\section{Viajar por pasear}

Antes que autores, somos personas y nuestros objetivos, deseos y miedos son, en gran cantidad de ocasiones, proyectados en la pantalla. Las películas de camino nacionales, según hemos visto, utilizan el motivo del viaje, muchas veces, sin necesitarlo. Al contrario de mucho del cine citado en el presente ensayo, en Costa Rica, el camino es incidental y los mismos relatos podrían haberse resuelto sin la necesidad de ir muy lejos. De acuerdo con ejemplos como Amor viajero (2017) o Maykol Yordan (2014), podríamos distinguir que el viaje, más que un elemento necesario para los personajes, puede serlo para sus creadores. No se podría encontrar una persona que diga que no le gusta visitar y conocer lugares hermosos e interesantes, tanto en el territorio nacional como en el exterior. Lamentablemente, la posibilidad de que los gustos personales se inmiscuyan en la realización de una película puede ir en detrimento de la calidad del relato. Muchas veces, los espectadores nos quedamos cuestionando, como hemos mencionado en apartados anteriores, sobre el porqué del viaje, ya que este no queda claro en pantalla.

\section{Huida de la introspección}

Cuando las respuestas no se pueden encontrar adentro, la naturaleza humana suele dictar buscarlas afuera. Este es un proceso natural, pero, se da, principalmente, de forma inconsciente. Los personajes de las road stories costarricenses suelen huir de la introspección 
de forma absolutamente consciente. Ejemplos como Entonces nosotros (2016), Tercer mundo (2009) y Amor viajero (2017), nos muestran cómo el relato conscientemente deriva en viajes que tienen el objetivo expreso de ayudar a mejorar una relación dañada.

Aquello que no se puede arreglar en casa se intenta mejorar en ruta. No obstante, en la mayoría de ocasiones, la solución se vuelve peor que el problema y los personajes terminan volviendo y se percatan del momento anterior, donde su estado inicial era mejor. Quizá, acá se evidencia una debilidad en la dramaturgia nacional, la incapacidad de contar historias verosímiles con personajes que realmente experimenten cambios profundos, lo cual nos lleva al siguiente punto siguiente.

\section{El camino como motor del proceso interno de los personajes}

Los problemas y el mundo interno de los personajes son difíciles de representar en un audiovisual. La experiencia como realizador me indica que, mucho de lo que he querido decir, en gran cantidad de ocasiones, se ha perdido entre la grabación y la edición. En algunos filmes costarricenses, donde los personajes se presentan en mundos estáticos, casi de encierro, como Agua fría de mar (2009), El sonido de las cosas (Murillo \& Escalante, 2016) o Abrázame como antes (Sánchez \& Ureña, 2016), el esfuerzo que deben hacer los realizadores para que el mundo interno de sus personajes se vea representado en pantalla es inevitablemente complejo y requiere de un proceso más riguroso en actuación y montaje, para que, así, salga a la luz la visión de sus autores. A pesar de lo anterior, al poner a los personajes en ruta y al llevarlos de un punto A hacia un punto B, la metáfora del camino hace parecer que hay un cambio interno en los personajes. Esto puede no tener resultados satisfactorios, pero, al menos, ofrece la apariencia de un cambio, aunque sea geográfico más que psicológico o conductual.

\section{Género de bajo presupuesto con altos valores de producción}

Tampoco es válido olvidarnos del contexto y de la producción. El atractivo que ha tenido la road movie como un género de bajo presupuesto, con la que no se necesitan grandes despliegues de producción, sets y efectos para lograr filmar locaciones visualmente impactantes, no es menor. Los realizadores y realizadoras costarricenses se han dado cuenta de esto. Nuestro país tiene un atractivo visual en varias zonas, de las cuales el Caribe sur ha sido especialmente favorecido por el cine nacional, dada su belleza escénica. Muchas películas que utilizan motivos de viaje han buscado estas bellas locaciones y, sin duda, ayuda a encontrar visuales de calidad sin gastar demasiado dinero. Sean cuales sean las razones que han llenado de caminos al cine costarricense, considero que el valor de reflexionar sobre las particularidades que va mostrando a lo largo de su desarrollo es muy alto. Esto con 
el fin de tomar conocimiento teórico y consolidar la práctica, de la misma manera que esta investigación es el motor que impulsó la creación de Hasta Llegar al Alba.

\section{Referencias}

Acuña, A. (2018). Dirección de cortometraje Hasta Llegar al Alba: El camino y el viaje en el cine costarricense (Tesis de licenciatura en Cine y Televisión). Universidad Véritas, San José, Costa Rica.

Barreto, B. \& Gastal, A. (Productores) y Amorim, V. (Director). (2003). O camino das nuvems [Película cinematográfica]. Brasil: Distribuida por Buena Vista Pictures.

Benedek, L. (Director). (1954). The wild one-extracto [Película Cinematográfica]. Estados Unidos: Columbia Pictures Corporation.

Bernal, S. (Directora). (2015). El lugar más feliz del mundo [Película Cinematográfica]. Costa Rica: Eagle Feather Films.

Berger, V. (2016a) Going Home: Mobility and Return Journeys, French and Spanish road movies. Transnational Cinemas, 7(2), 168-182.

Berger, V. (2016b) Travelling Cinema - La road movie latinoamericana en el contexto global. Foro Hispánico, 51, 159-178.

Bonfire, M. (1968). Born to be wild [Canción grabada por Steppenwolf].

Bossi, P., Lauría, H., Mentasti, C., Ramos, F., Saúl, A. (Productores) \& Mignona, E. (Director). (2003). Cleopatra [Película cinematográfica]. Argentina: Patagonik Film Group.

Bustamante, D., Gallego, C. (Productores) \& Guerra, C. (Director). (2009). Los viajes del viento [Película cinematográfica]. Colombia-Alemania-Holanda-Argentina: Distribuida por Cineplex.

Capra, F. (Director), \& Riskin, R. (Escritor). (1934). It Happened One Night [Película Cinematográfica]. Estados Unidos: Columbia Pictures Corp.

Castro, L. (Productor) y Yasin, I. (Directora). (2008). El camino [Película cinematográfica]. Costa Rica-Francia: Astarté Films.

Chanan, M. (2016). El discurso espacial de la road movie en América Latina. Foro Hispánico, 51, 179-185.

Cole, C., Ávila-Tacsan, L. (Productores) \& Jiménez, H. (Director). (2016). Entonces nosotros [Película cinematográfica]. Costa Rica: Evoke.

ESCENA. Revista de las artes, 2020, Vol. 79, Núm. 2 (enero-junio), pp. 80-98 
Cortés, M. (2016). Fabulaciones del nuevo cine costarricense. San José, Costa Rica: URUK Editores.

Cortés, M. (2005). La pantalla rota 100 años de cine centroamericano. México: Taurus Historia.

Cuarón, A. \& Vergara, J. (Productores) \& Cuarón, A. (Director). (2001). Y tu mamá también [Película cinematográfica]. México: Distribuida por IFC Films y 20th Century Fox.

Eyerman, R \& Löfgren O. (1995). Romancing the Road: Road Movies and Images of Mobility. Theory, Culture \& Society, 12, 53-79.

Fábrega, P. (Directora). (2008). Agua fría de mar [Película cinematográfica]. Costa Rica: Temporal Films.

Fábrega, P. (Directora). (2015). Viaje [Película cinematográfica]. Costa Rica: Mosaico Filmes.

Feldman, P. (Productor) \& Peckinpah, S. (Director). (1968). The Wild Bunch [Película cinematográfica]. Estados Unidos: Warner Bros-Seven Arts.

Fonda, P. (Productor) \& Hopper, D. (Director). (1969). Easy Rider. [Película cinematográfica]. Estados Unidos: Distribuida por Columbia Pictures.

Ford, J. (Director). (1940). Grapes of Wrath. [Película cinematográfica]. Estados Unidos: Distribuida por 20th Century Fox.

Gómez, D., (Productor), \& Gómez, M. (Director). (2012). El fin [Película cinematográfica]. Costa Rica: Atómica Films.

Gómez, D., Calvo, J. (Productores), \& Gómez, M. (Director). (2017). Amor viajero [Película cinematográfica]. Costa Rica: Atómica Films.

Gómez, M. (Director). (2008). El cielo rojo [Película cinematográfica]. Costa Rica: Ginaluvosi Producciones.

Gómez, M. (Director). (2014). Maykol Yordan de Viaje perdido [Película cinematográfica]. Costa Rica: Audiovisuales LMD.

Granda, M. (Productor), \& Jiménez, H. (Director). (2011). El regreso. [Película cinematográfica]. Costa Rica: Miel y Palo Films.

Jiménez, A. (Productora) \& Caro, C. (Director). (2011). Tercer mundo [Película cinematográfica]. Costa Rica: Filamento Films.

Kerouac, J. (1957). On the Road. New York: Penguin. 
Laughlin, M. (Productor) \& Hellman, M. (Director). (1971). Two Lane Blacktop. [Película cinematográfica]. Estados Unidos: Distribuida por Universal Pictures.

Malick, T. (Director). (1973). Badlands [Película cinematográfica]. Estados Unidos: Distribuida por Warner Brothers.

Murillo, M. (Productora), \& Escalante, A. (Director). (2016). El sonido de las cosas [Película cinematográfica]. Costa Rica: Sputnik Films.

Pérez, E. (Productor) y Acuña, A. (Director). (2018). Hasta llegar al alba [Película cinematográfica]. San José, Costa Rica.: Pro In Films.

Rivera, M., García, J. (Productores), y Jiménez, H. (Director). (2010). A ojos cerrados [Película cinematográfica]. Costa Rica: Miel y Palo Films.

Salguero, M. (Director). (1968). La apuesta [Película cinematográfica]. Costa Rica.

Salles, W. (Director). (1998). Central do Brasil [Película cinematográfica]. Brasil-Francia: Videofilmes - MACT Productions.

Sánchez, G. (Productor), y Ureña, J. (Director). (2016). Abrázame como antes [Película cinematográfica]. Costa Rica: Producciones la Ventana.

Scott, R. (Director). (1991). Thelma and Louise [Película cinematográfica]. Estados Unidos: Distribuida por Metro-Goldwin-Mayer.

Solanas, F. (Director). (1992). El viaje [Película Cinematográfica]. Argentina: Trigon Film.

Tenenbaum, E., Nozik, M., Tekhoff, K. (Productores) \& Salles, W. (Director). (2004). Diarios de Motocicleta [Película cinematográfica]. México: Distribuida por Buena Vista International, Pathé y Focus Features.

Urbini, M. (Productor), \& Bertoni, A.F. (Director). (1930). El retorno [Película cinematográfica]. Costa Rica: Albert Francis Bertoni.

Wenders, W. (Director). (1994). París, Texas [Película cinematográfica]. Barcelona: Fil$\max$. 